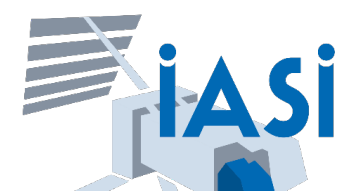

\section{Large VOC enhancements in recent massive wildfires observed from space}

Bruno Franco ${ }^{1}$, L. Clarisse ${ }^{1}$, J. Hadji-Lazaro², D. Hurtmans ${ }^{1}$,

G. Lecomte ${ }^{1}$, S. Turquety ${ }^{3}$, C. Clerbaux ${ }^{2,1}$, and P.-F. Coheur ${ }^{1}$

${ }^{1}$ Université Libre de Bruxelles (ULB), Spectroscopy Quantum Chemistry and Atmospheric Remote Sensing (SQUARES),

¿2ATMOS/IPSL, Sorbonne Université, UVSQ, CNRS, Paris, France

${ }^{3}$ Laboratoire de Météorologie Dynamique (LMD)-IPSL, Sorbonne Université, CNRS UMR 8539 Ecole Polytechnique, Paris, France

EGU General Assembly, $8^{\text {th }}$ May 2020, Vienna, Austria

EGU2020-20243

https://doi.org/10.5194/egusphere-egu2020-20243 


\section{Overview}

Massive wildfires erupted in Amazonia and through the subarctic region in summer 2019, and in Australia in winter 2019-2020. During such biomass burning events, sizeable amounts of volatile organic compounds (VOCs) were emitted directly by the fires as well as rapidly produced in plumes via the degradation of short-lived gas precursors.

Nadir-viewing infrared sensors onboard meteorological satellites, such as IASI (Infrared Atmospheric Sounding Interferometer) embarked on the Metop platforms, provide global and spatially dense observations that are very useful to track biomass burning events throughout the globe and to provide trace gas quantification in fire plumes.

We apply a general retrieval framework, based on an artificial neural network, to derive the integrated abundance (total column) of several major VOCs from the infrared radiance spectra recorded by IASI. Here, we present daily regional snapshots of VOC enhancements in the plumes from the recent Amazonian, Australian and subarctic wildfires.

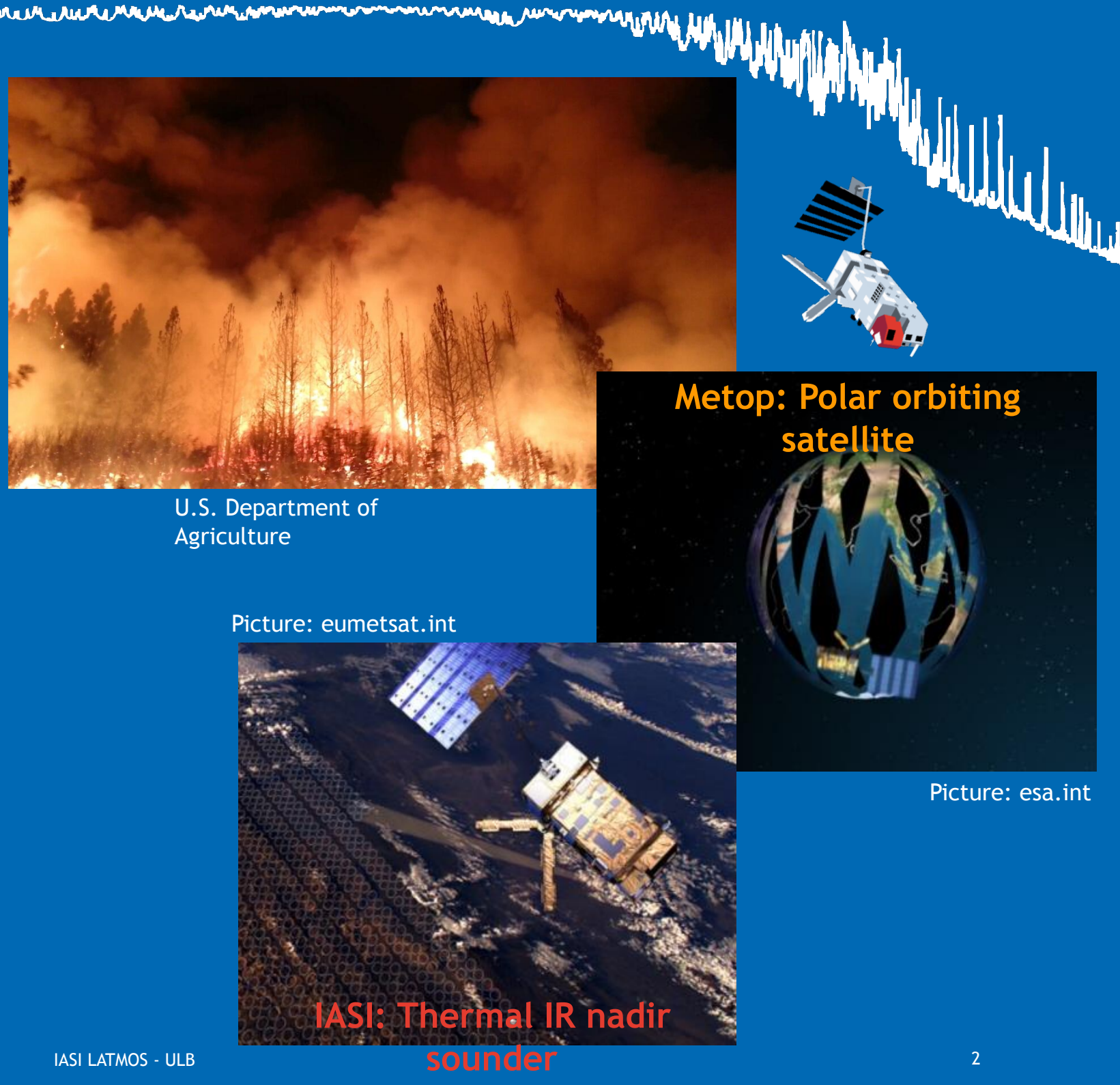


The ANNI (Artifical Neural Network for IASI) retrieval framework consists, for each individual spectrum, in the calculation of a Hyperspectral Range Index (HRI) to quantify the target gas absorption in the spectrum, and in its subsequent conversion into gas integrated abundance (total column) using an artificial feedforward neural network accounting for the state of the atmosphere and surface.

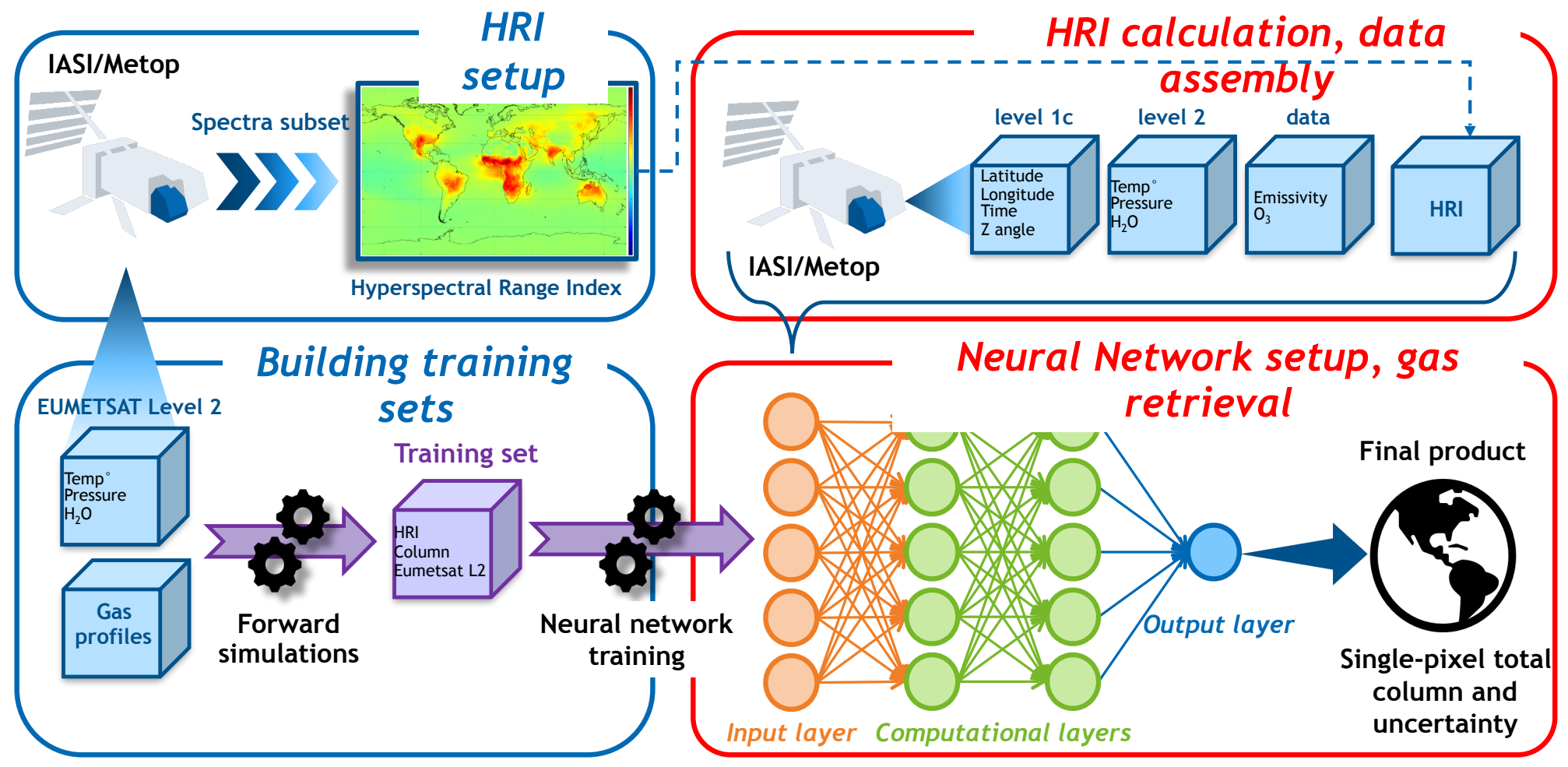

Franco et al (2018) J. Geophys. Res.: Atmos., 123 (24), 13,963-13,984. https://doi: $10.1029 / 2018 \mathrm{jd} 029633$

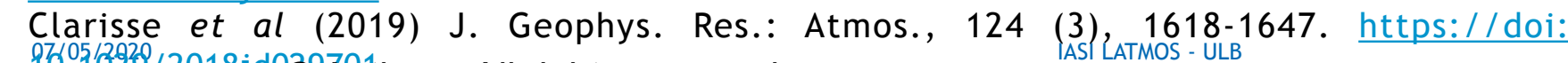

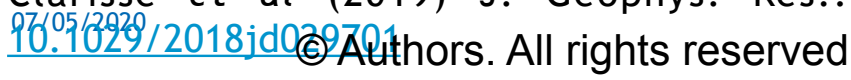

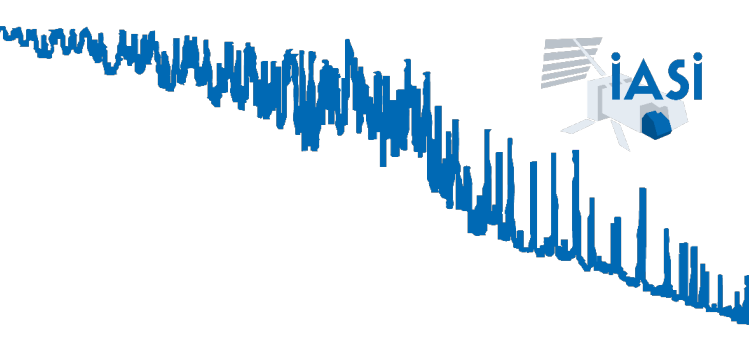

This retrieval method reveals particularly sensitive to the detection of weak, sometimes broadband, infrared absorbers, while its computing efficiency permits the processing of the entire IASI observational time series (2007 - ...).

Quasi-global distributions of single-pixel total columns and associated uncertainties are produced twice-daily (a.m. and p.m. satellite overpasses). 
2. Originally developed for the retrieval of ammonia $\left(\mathrm{NH}_{3}\right)$ and dust, the ANNI framework now permits also the retrieval of a suite of VOCs:

- Methanol $\left(\mathrm{CH}_{3} \mathrm{OH}\right)$, formic acid $(\mathrm{HCOOH})$ and PAN $\left(\mathrm{CH}_{3} \mathrm{C}(\mathrm{O}) \mathrm{O}_{2} \mathrm{NO}_{2}\right)$ Franco et al (2018), JGR, 123 (24), 13,963-13,984. https://doi:10.1029/2018jd029633

- Acetone $\left(\mathrm{CH}_{3} \mathrm{C}(\mathrm{O}) \mathrm{CH}_{3}\right)$

Franco et al (2019), GRL, 46, 2884-2893. https://doi.org/10.1029/2019GL082052

- Acetic acid $\left(\mathrm{CH}_{3} \mathrm{COOH}\right)$

Franco et al (2020), GRL, 47, e2019GL086239. https://doi.org/10.1029/2019GL08623.

- Acetylene $\left(\mathrm{C}_{2} \mathrm{H}_{2}\right)$ and hydrogen cyanide $(\mathrm{HCN})$

$\rightarrow$ under development

- Ammonia $\left(\mathrm{NH}_{3}\right)$

Van Damme et al (2017), AMT, 10(12), 4905-4914. https://doi.org/10.5194/amt-10-49 Whitburn et al (2016), JGR, 121, 6581-6599. https://doi.org/10.1002/2016jd024828

- Dust

Clarisse et al (2019), JGR, 124 (3), 1618-1647. https://doi:10.1029/2018jd029701

07/05/2020

(C) Authors. All rights reserved
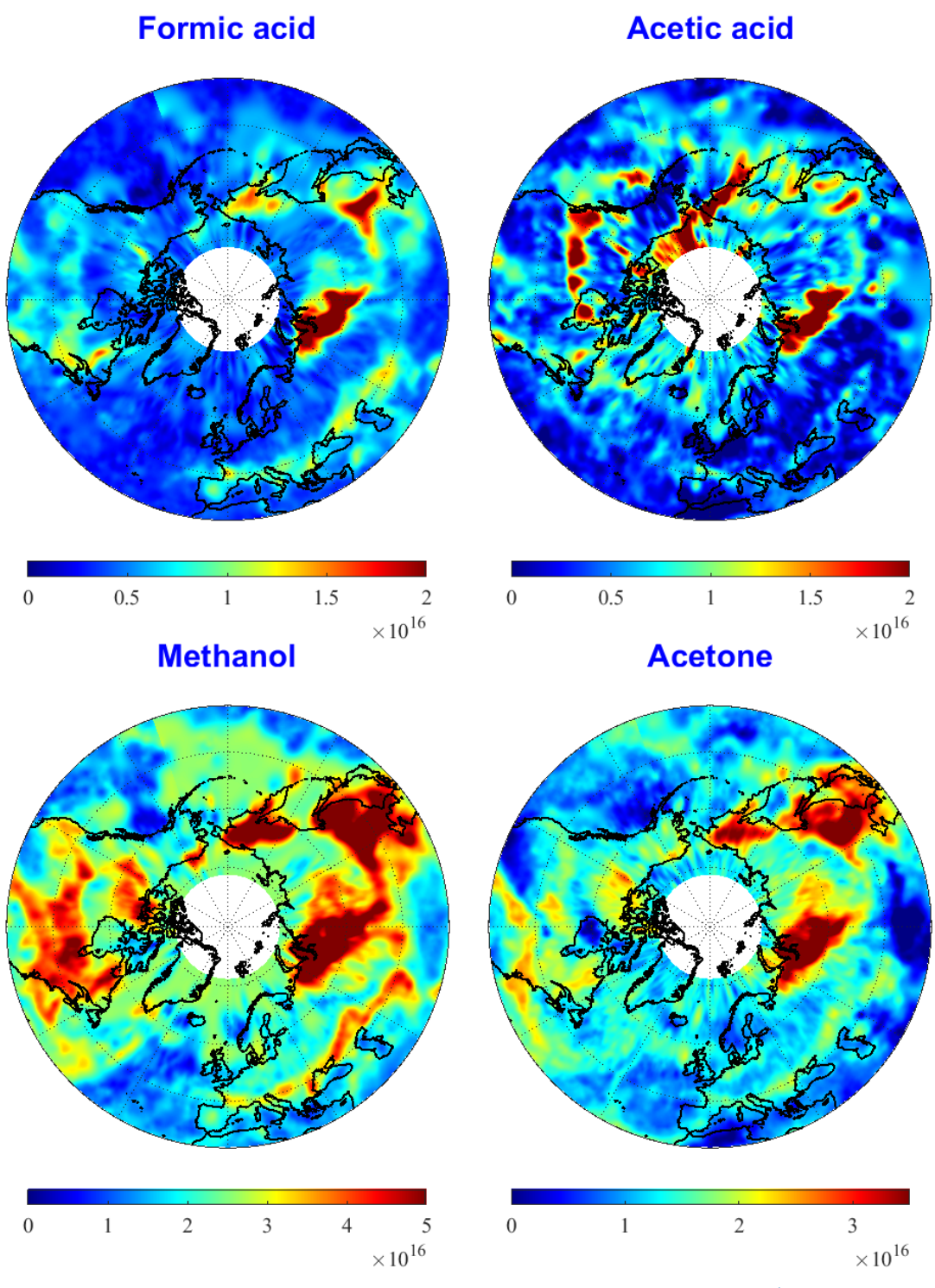

IASI LATMOS - ULB 
IASI/Metop-A \& -B

\section{3.}

2019

Amazonian wildfires

$07 / 05 / 2020$
Formic acid

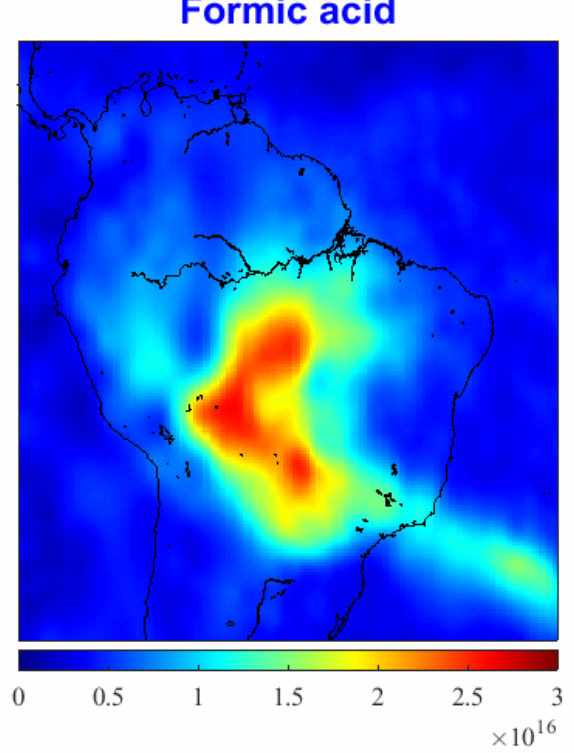

Methanol

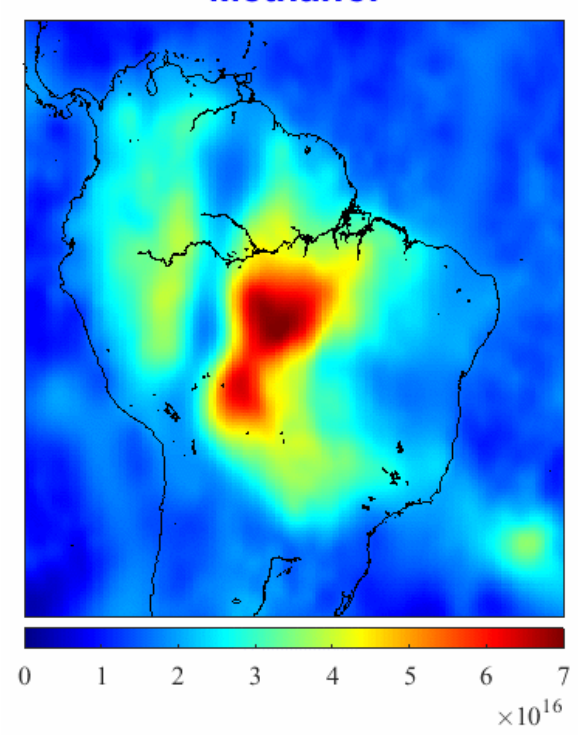

Sep-04-2019

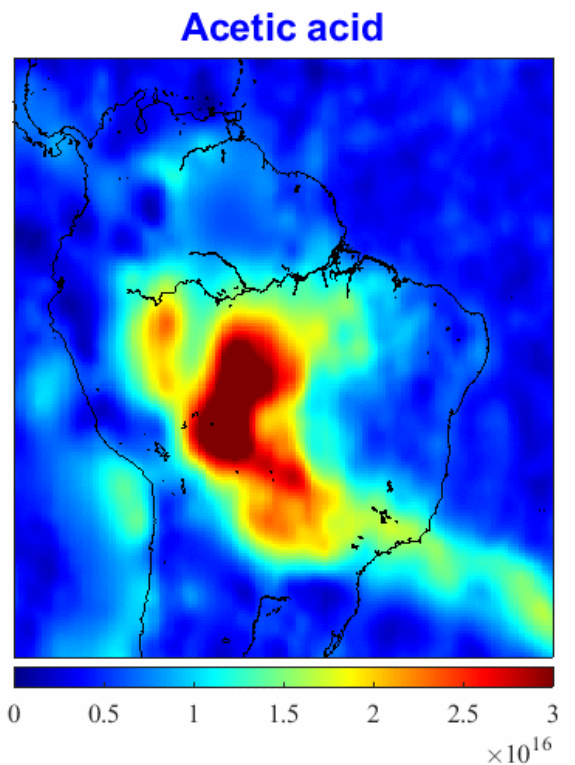

Acetylene

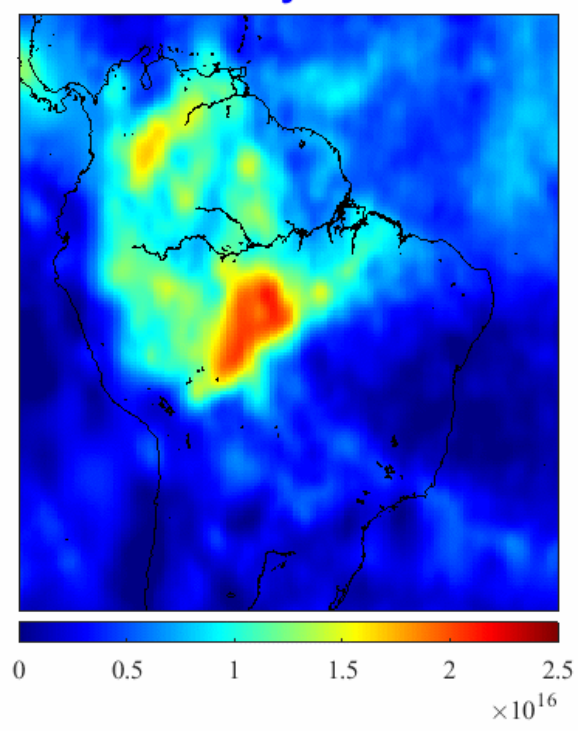

PAN

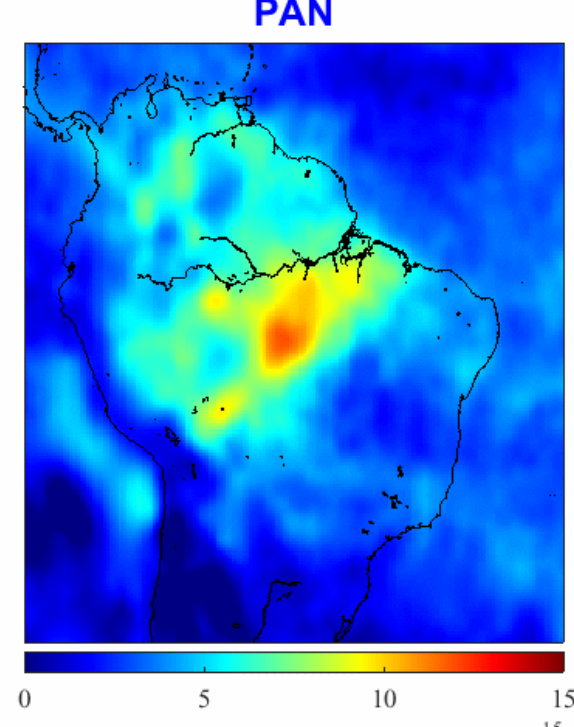

Hydrogen cyanide

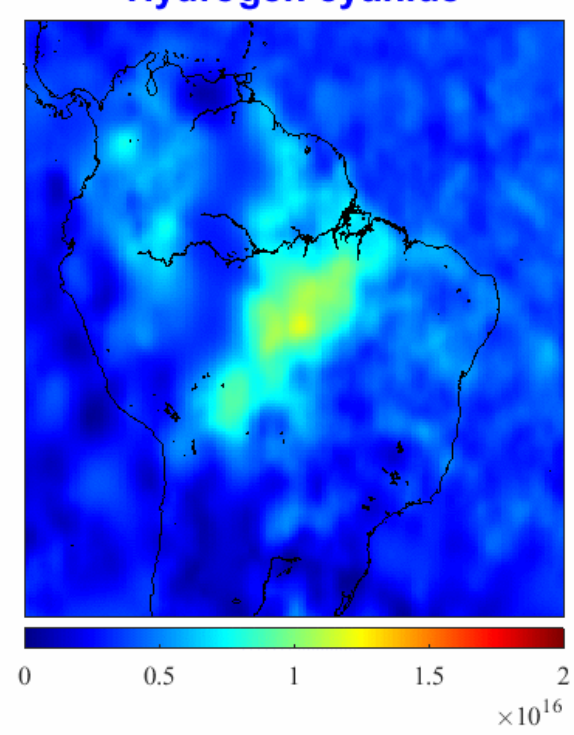

Gas total column (molecules $\mathrm{cm}^{-2}$ ) Ammonia
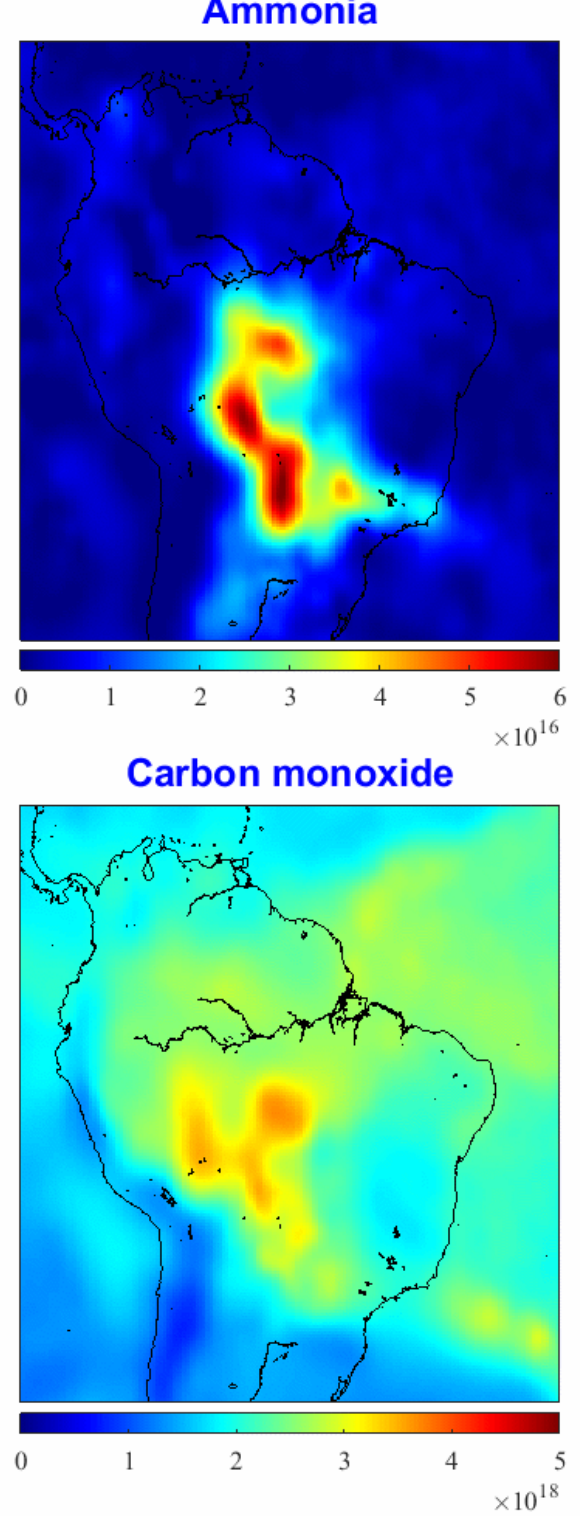
(C) Authors. All rights reserved

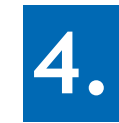

IASI/Metop-A \& -B
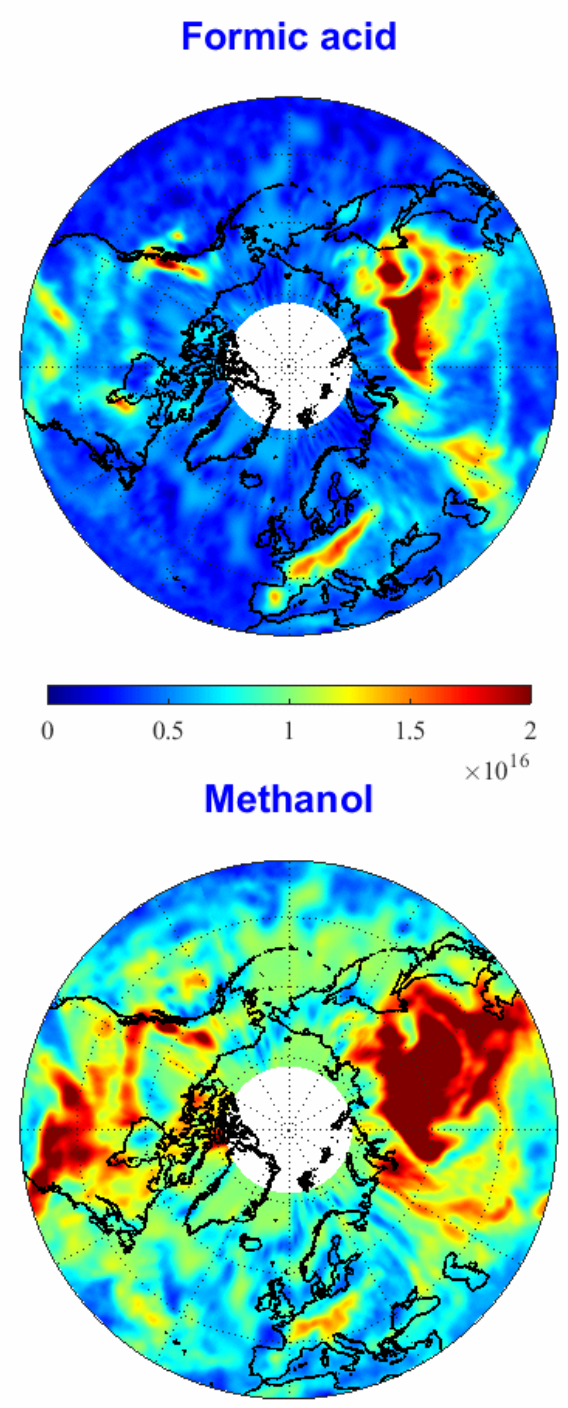

07/05/2020

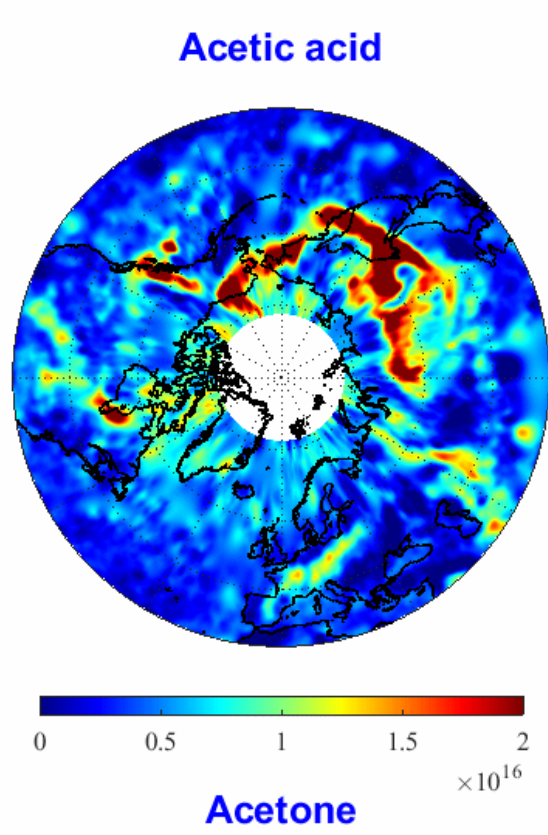

Jul-01-2019
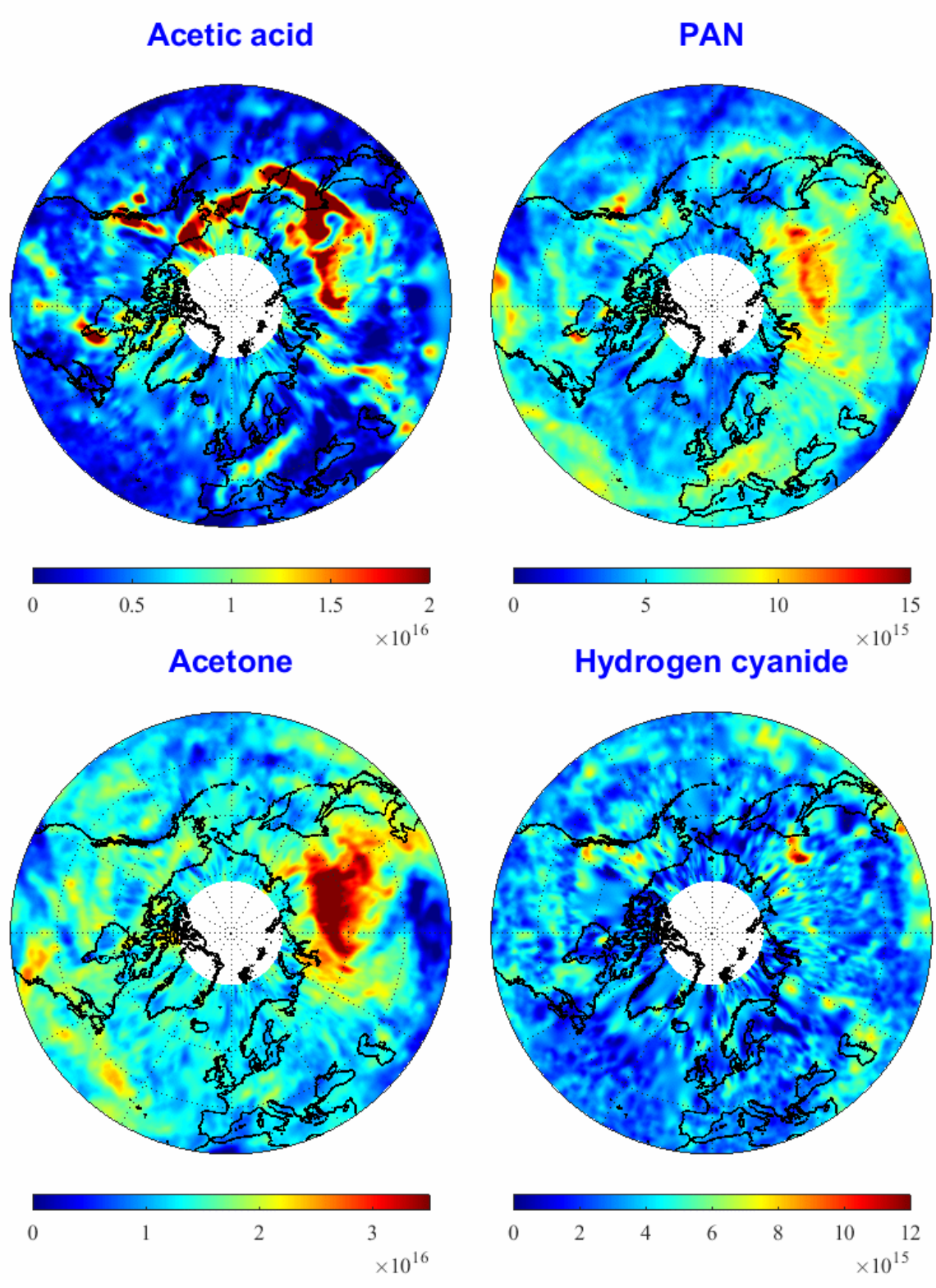

Gas total column (molecules $\mathrm{cm}^{-2}$ )

Ammonia
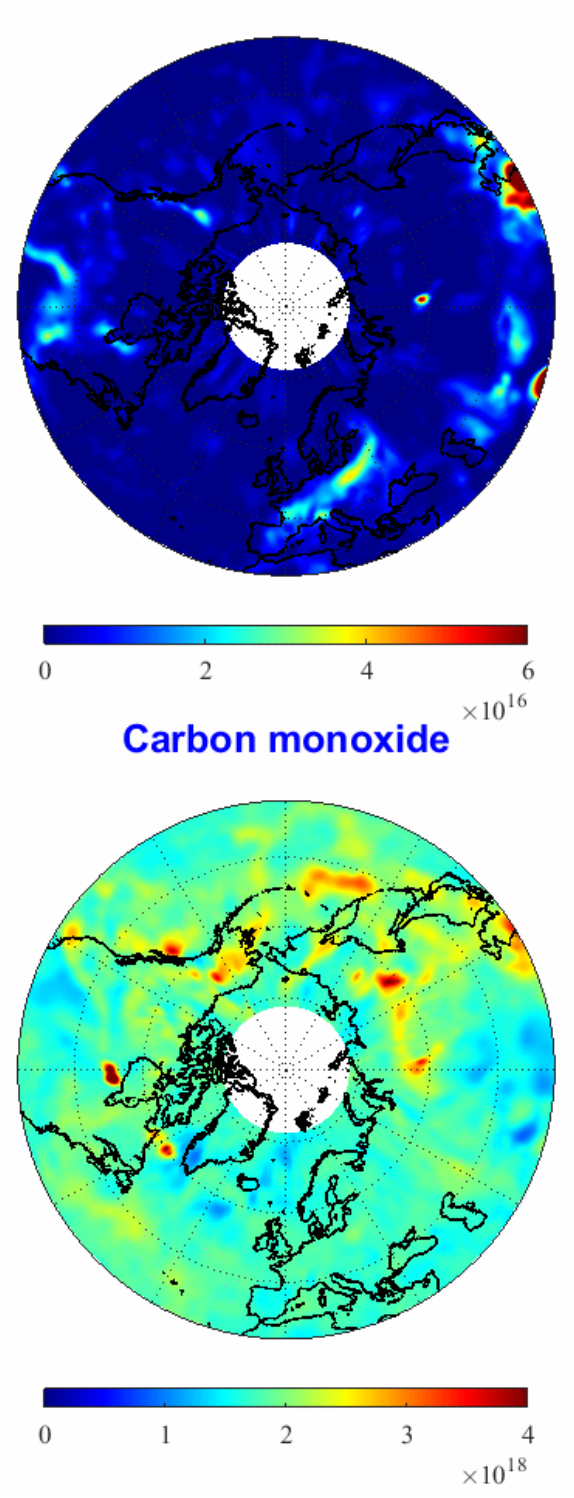
(C) Authors. All rights reserved 5.

2019-2020 Australian bushfires

07/05/2020
IASI/Metop-A \& -B
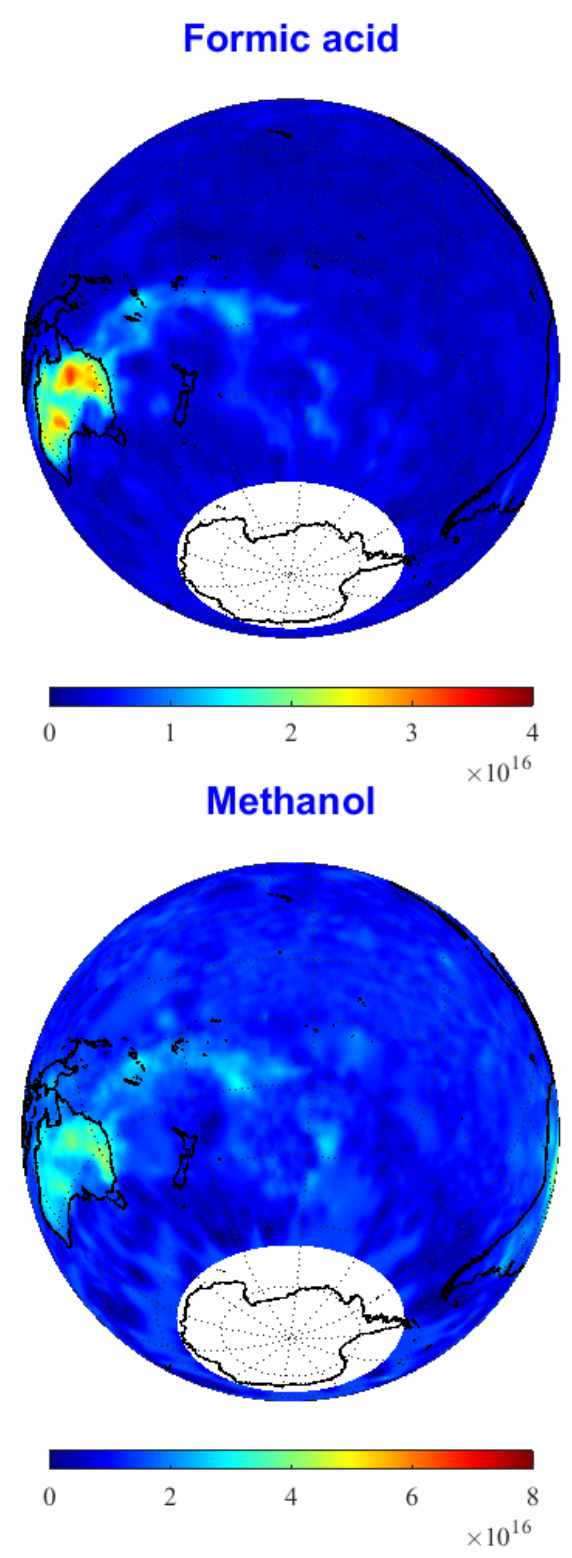

Dec-23-2019

Acetic acid
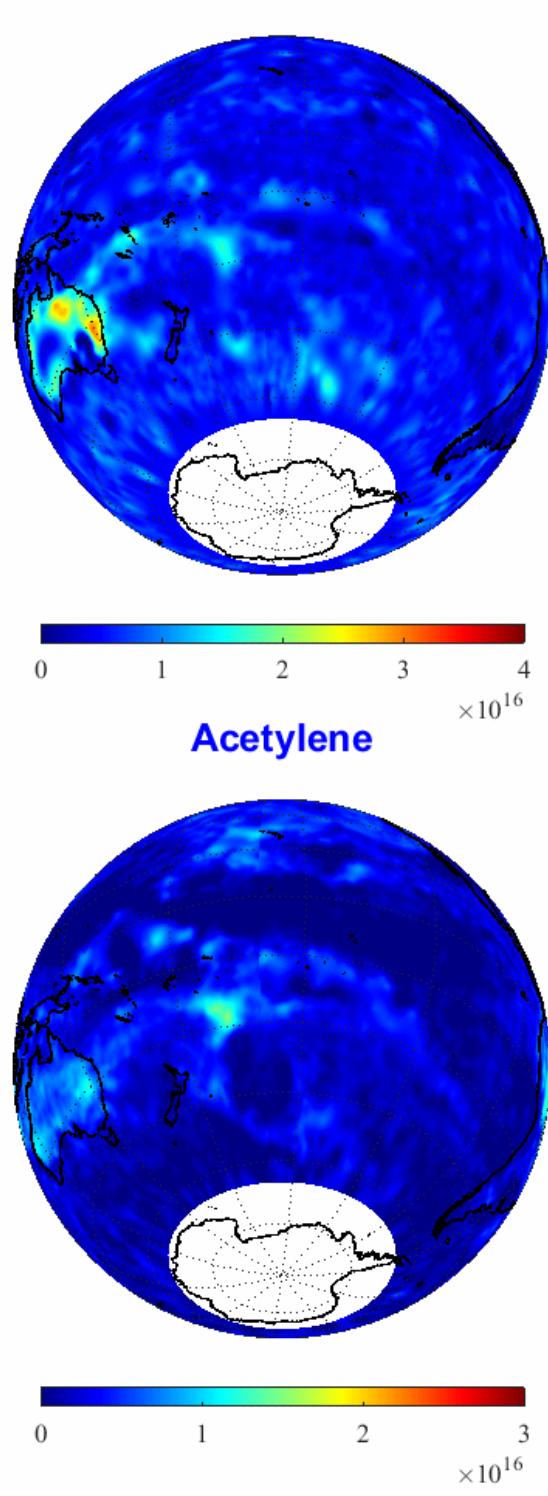

Gas total column (molecules $\mathrm{cm}^{-2}$ )

PAN
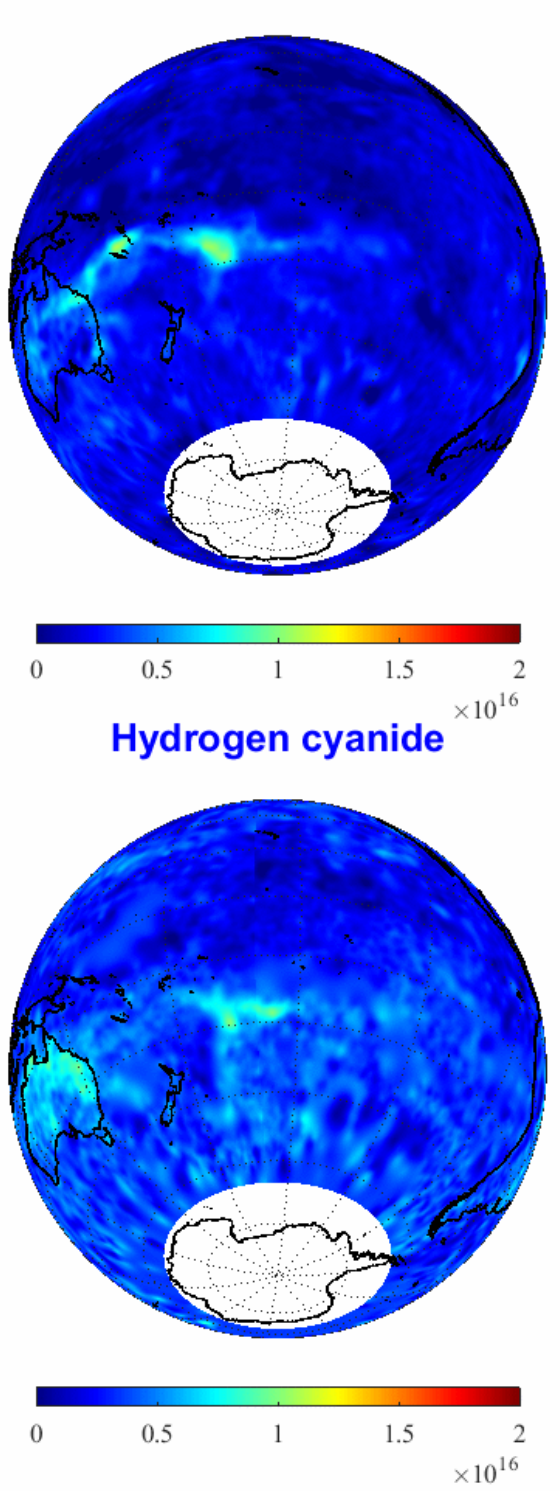

Ammonia
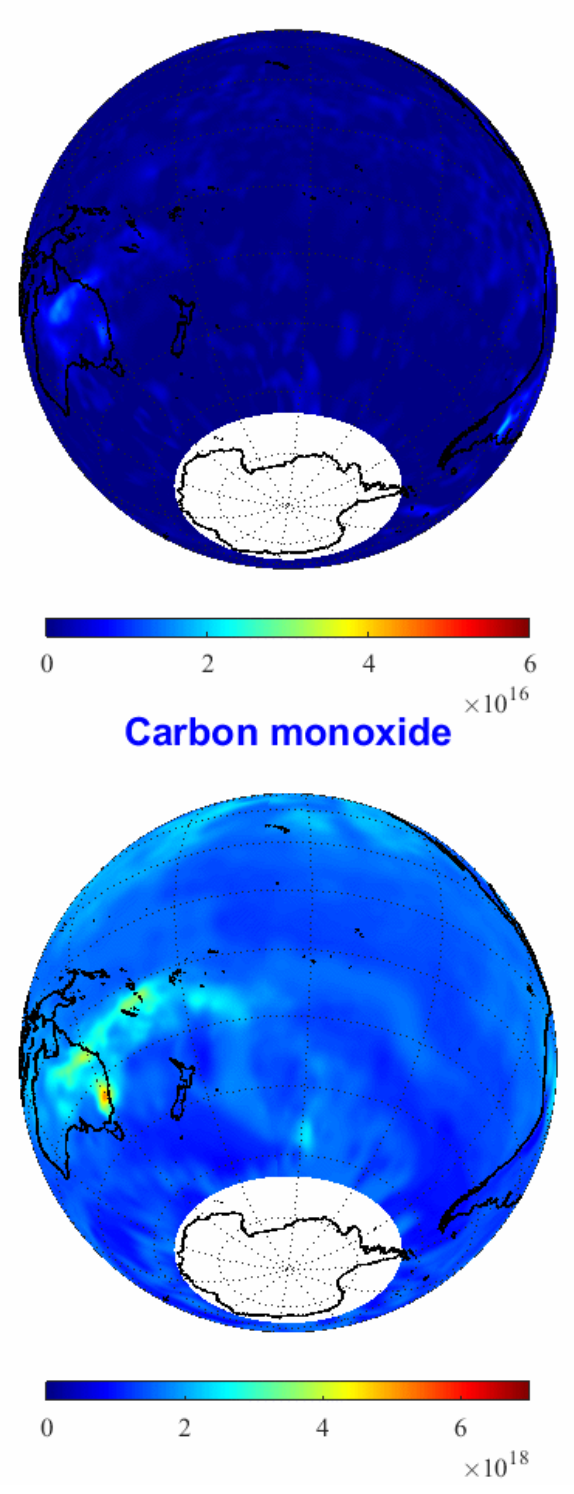


\section{Acknowledgements}

The research has been supported by the project OCTAVE (Oxygenated Compounds in the Tropical Atmosphere: Variability and Exchanges (http://octave.aeronomie.be/) of the Belgian Research Action through Interdisciplinary Networks (BRAIN-be; 2017-2021; Research project BR/175/A2/OCTAVE) and by the IASI.Flow Prodex arrangement (ESA-BELSPO).

L. Clarisse is a research associate supported by the F.R.S.-FNRS.

The French scientists are grateful to CNES and Centre National de la Recherche Scientifique (CNRS) for financial support.

IASI is a joint mission of Eumetsat and the Centre National d'Etudes Spatiales (CNES, France). The IASI Level-1C data are distributed in near real-time by Eumetsat through the EumetCast distribution system. The authors acknowledge the AERIS data infrastructure (https://www.aeris-data.fr/) for providing access to the IASI Level-1C data and Level-2 temperature data. 